\title{
Hydrocortisone Hemisuccinate
}

National Cancer Institute

\section{Source}

National Cancer Institute. Hydrocortisone Hemisuccinate. NCI Thesaurus. Code C61786.

The synthetic hemisuccinate salt form of hydrocortisone, a corticosteroid with antiinflammatory and immunosuppressive properties. Hydrocortisone acetate initially binds to the cytoplasmic glucocorticoid receptor; then the receptor-ligand complex is translocated to the nucleus where it initiates the transcription of genes encoding for antiinflammatory mediators, such as cytokines and lipocortins. Lipocortins inhibit phospholipase A2, thereby blocking the release of arachidonic acid from membrane phospholipids and preventing the synthesis of prostaglandins and leukotrienes. 